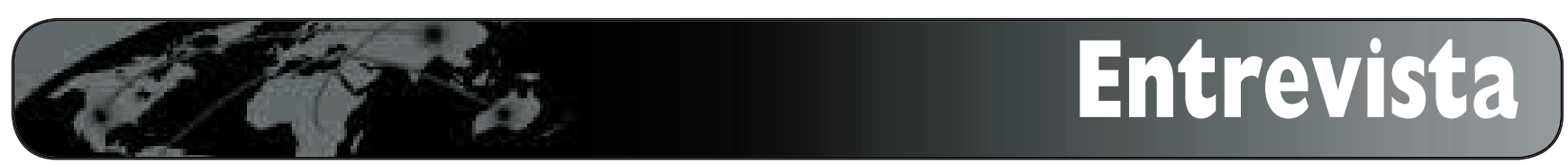

\title{
Conflicto de intereses en la publicación médica: el punto de vista del autor
}

José Ma Martín Moreno. “Conflicto de intereses en la publicación médica: el punto de vista del autor”. En: El profesional de la información, 2007, enero-febrero, v. 16, n. 1, pp. 84-86. http://dx.doi.org/10.3145/epi.2007.ene.11

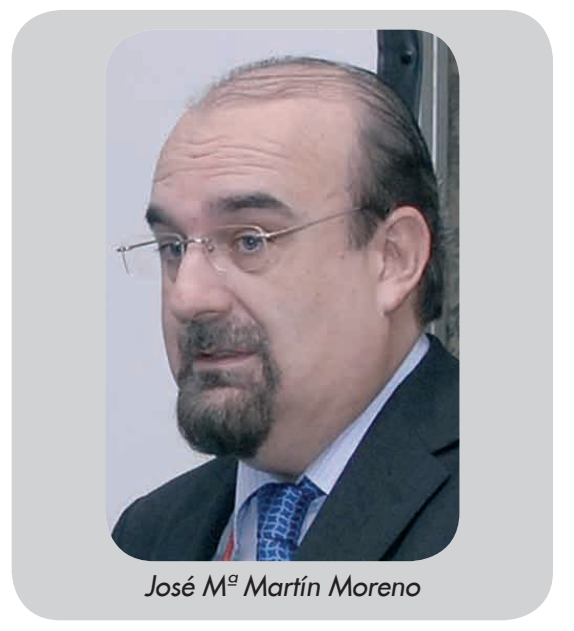

CON MOTIVO DE LA JORNADA organizada por la Fundación Lilly sobre "La publicación médica en España: calidad, relevancia, impacto, visibilidad y proyección", El Escorial, Madrid, 20 de noviembre de 2006, entrevistamos al doctor José $M^{a}$ Martín Moreno, catedrático de medicina preventiva y salud pública de la Universidad de Valencia

Desde la perspectiva del autor... ¿por qué esa obsesión por publicar?

- En primer lugar porque una investigación no acaba hasta que no se comunica a la comunidad científica, y esto se hace a través de la publicación de un trabajo (artículo) en una revista o medio indizado. Además, el peer review (revisión por pares) supone de por si una "validación" del trabajo escrito, y éste sirve para dar a conocer la propia investigación (que es identificada y accesible a través de repositorios) y ofrecer la posibilidad de comparar los resultados con los de otros estudios, y de repetir el estudio, verificándolo o refutándolo.

Pero es que, complementariamente, y más allá de las consideraciones formales antes expuestas, no podemos olvidar que la publicación supone un mérito que se tiene en cuenta y que puede determinar aspectos profesionales de un médico o, en general, de un investigador. De hecho, el ritual y resultado de publicación supone un medio de evaluar nuestro rendimiento y representa un indicador utilizado para la carrera profesional. Es más, en ciertos ámbitos universitarios y científicos es bien conocido el dicho: "en este mundo... o publicas o mueres".

¿Qué debe exigírsele a los editores de revistas científicas para posibilitar las condiciones básicas para las publicaciones que necesitan los autores?

- Los responsables de las revistas científicas tienen el reto de asegurarse de que el contenido de sus publicaciones sea de calidad, es decir, exacto, válido, fiable, ético, verosímil e inteligible. Para ello, la elección y supervisión de los evaluadores (también denominados árbitros o referees) es fundamental. Además, es esencial proporcionar normas que sean útiles a las revistas biomédicas a la hora de definir políticas y procedimientos en conexión con los conflictos de intereses en el arbitraje científico.
¿Cuándo surge el conflicto de intereses?

- Se han caracterizado en ocasiones circunstancias en las cuales un autor, director de revista o árbitro tiene intereses que entran en conflicto o compiten entre sí y que podrían redundar en parcialidad o en decisiones inapropiadas. Estos conflictos de intereses pueden ser potenciales o tan solo percibidos, y requieren adecuada atención en todos los casos.

Conflictos sí, pero... ¿qué tipo de conflictos?

- Por un lado, hoy se da la frecuente realidad de investigación médica promovida y patrocinada por la industria farmacéutica (o alimentaria, o de tecnologías médicas...). Empecemos reconociendo que es no sólo lícito, sino también necesario que la industria promueva investigación y presente la información sobre sus productos, pero es exigible que lo haga con la mayor transparencia posible, para evitar el temido conflicto de intereses "económico". Para ello, y en el rol de autores, es nuestra responsabilidad poner en marcha todos los mecanismos necesarios para evitar que se pierda la confianza de la sociedad en los profesionales médicos, en la investigación y en su posibilidad de desarrollo futuro. En primer lugar, es inexcusable la declaración de los conflictos de intereses de los investigadores que publican en las revistas médicas, circunstancia que ya se exige en la mayoría de las re- 
vistas importantes y que suscribe el código ético de numerosas revistas. Este simple requisito puede influir en la percepción de los resultados de un determinado artículo, pero es necesario para asegurar transparencia y minimización de los sesgos de interpretación del lector. Complementariamente a lo anterior, y de acuerdo con lo que propone el prestigioso editor Richard Smith uno de los elementos que hemos de defender es que sean los investigadores, y no los patrocinadores, los que conserven el control sobre el diseño, el análisis y la publicación de los resultados de sus investigaciones. Por otro lado, se impone la necesidad de conocer también aquellas investigaciones cuyos resultados no han sido "favorables", así como fomentar revisiones sistemáticas independientes que ayuden a los clínicos en sus procesos de decisión diagnóstica o terapéutica

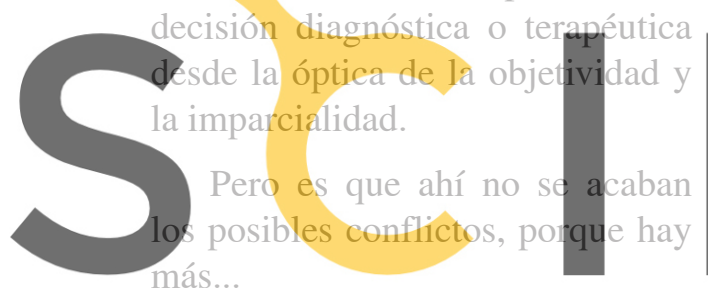

Register for free at https//www.scipe

-Pueden darse "intereses particulares" que pueden ser de muy diverso orden. Se citan dimensiones diversas, entre las cuales estarían la intelectual, política, o académica. No olvidemos que a veces surgen (o se perciben) conflictos de intereses que afectan a los evaluadores o árbitros, que no sólo se producen por motivos económicos, sino también por rivalidad, competencia académica en materia científica y tecnológica, e incluso valores y creencias ideológicas.

Danos ejemplos de rivalidades que hayan podido reflejarse en conflicto de intereses

- Hay evaluadores que han aprovechado indebidamente la ven- taja facilitada por la revisión de un trabajo novedoso...

Por ejemplo, el caso PeruchoVogelstein es de dominio público. Manuel Perucho, científico de reconocido prestigio nacido en Albacete y que en los noventa trabajaba en el Burnham Institute de California, identificó alteraciones genéticas asociadas al cáncer de colon. Envió para publicación sus hallazgos a una revista del máximo prestigio científico y el trabajo fue rápidamente aceptado, pero su publicación se retrasó por asuntos de naturaleza 'editorial'. Mientras tanto, y antes de que el trabaio viera la luz, Perucho dio una presentación en una reunión científica organizada por la Fundación Ramón Areces. Bert Vogelstein estuvo presente y le preguntó sobre el tema. Perucho le describió los detalles pues no desconfió de la ética de Volgestein. el mérito único de haber encontrado lo que causaba el sida. Montagnier acusaba a Gallo de haberle robado una muestra del Instituto Pasteur. Tuvo que entrar la revista Nature a archivar la cuestión. En 1987, y tras múltiples negociaciones, tanto Gallo como Montagnier se avinieron a considerarse co-descubridores del retrovirus: Montagnier y sus colaboradores fueron los primeros en identificar el VIH (virus de la inmunodeficiencia humana); Gallo y los suyos fueron los primeros en establecer una relación entre el VIH y el sida. Y es que de la "paternidad" del hallazgo dependen muchos intereses.

En cualquier caso, y aun reconociendo la importancia de lo anterior, lo verdaderamente trascendente es responder a las necesidades de la población, y no tanto al narcisismo o intereses particulares

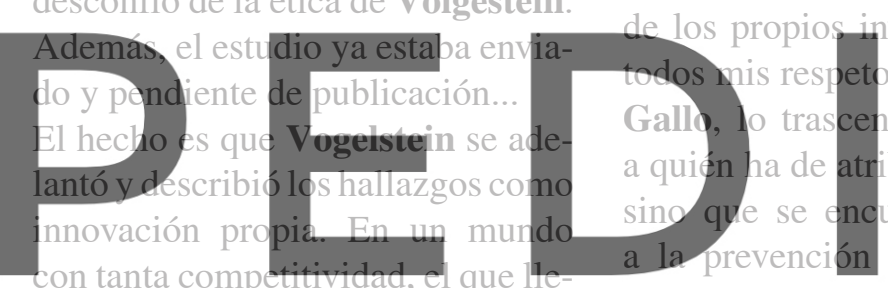
investigadores. Con
tos a Montagnier y
ribuírsele el mérito
cuentre la solución
y tratamiento del

ga primero marca la diferencia...

sida. Esa misma línea argumental

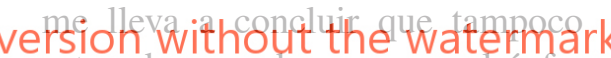
estoy de acuerdo en poner el énfasis en fraudes puntuales o en culen 1998 con el Nobel de Medicina otorgado a Robert F. Furchgott, Louis J. Ignarro y Ferid Murad (todos de EUA), por haber descubierto que el gas óxido nítrico es una molécula transmisora de señales dentro del sistema cardiovascular. Hay indicios de retrasos previos en publicaciones, y evidencias de un cierto sesgo, que hicieron que Salvador Moncada (natural de Honduras) no fuera uno de los elegidos para el prestigioso galardón.

¿Hasta qué punto esos conflictos de intereses conllevan situaciones preocupantes?

- Es algo que ciertamente puede afectar al crédito y la carrera de un investigador. Un ejemplo "clásico" es el de Robert Gallo y Luc Montagnier. Ambos querían pabilizar a la industria farmacéutica de inventar enfermedades para ganar más dinero. No es cuestión de inventarse enfermedades porque, desgraciadamente, día a día vemos que las enfermedades están ahí, y la gente las sufre. Nuestro papel como investigadores y médicos es intentar buscar soluciones. Tal y como ocurrió en el caso del sars (severe acute respiratory syndrome) en el año 2003, en el que hubo una sinérgica colaboración que contribuyó a la identificación y caracterización del coronavirus causante de la enfermedad que hasta ese momento había generado tanto pánico...

Y entonces ¿cuál sería una posible recomendación sobre el asunto? 
- A mi juicio es preferible abordar el tema con valentía y no reprimir la capacidad de comunicación y envío de trabajos para publicación. Tengo la suerte de haber aprendido mucho sobre las posibles soluciones a partir de mi participación en un comité del que formo parte en el IARC de Lyon. Ahí, hemos podido conocer el reciente trabajo sobre promoción de la integridad en revistas científicas elaborado por el Consejo de Editores Científicos (Council of Science Editors. CSE's White Paper on Promoting Integrity in Scientific Journal Publicatio$n s$, 2006). En último extremo creo que es mejor pecar por exceso de divulgación que por defecto. Estoy convencido que la verdad tenderá siempre a emerger. Para ello los autores pueden y deben prestar su transparente colaboración a los directores de revistas, que sabrán elegir los evaluadores apropiados y la información que los lectores deben conocer en conexión con los posibles conflictos de intereses.

\section{Bibliografía}

Cooper, R. J.; Gupta, M.; Wilkes, M. S.; Hoffman, J. R. "Conflict of interest disclosure policies and practices in peer-reviewed biomedical journals". En: J. Gen Intern. Med., 2006, vol. 21, pp. 1248-1252.

Jørgensen, A. W.; Hilden, J.; Gøtzsche P. C. "Cochrane reviews compared with industry supported meta-analyses and other meta-analyses of the same drugs: systematic review". En: BMJ, 2006, n. 333, pp. 782-786. Epub: 2006 Oct 6

Krimsky, S.; Rothenberg, L. S. "Conflict of interest policies in science and medical journals: editorial practices and author disclosures". Sc Eng Ethics, 2001, vol. 7, pp. 205-218.

Martín-Moreno, S. "Ética de la prescripción.
Conflictos del médico con el paciente, la entidad gestora y la industria farmacéutica". Med Clin (Barc), 2001, n. 116, pp. 299-306.

Regehr, G.; Bordage, G. "To blind or not to blind? What authors and reviewers prefer". En: Med Educ, 2006, vol. 40, pp. 830-831.

José Martín Moreno, Catedrático de Medicina preventiva y salud pública, Universidad de Valencia. Asesor de la Regional Office for Europe y de la International Agency for Research on Cancer, ambas de la World Health Organization (WHO).

Av. Blasco Ibáñez, 15. 46010 Valencia.

Tel.: +34-963 864 997; fax: 963 864166

jmarmor@telefonica.net

jose.maria.martin@uv.es
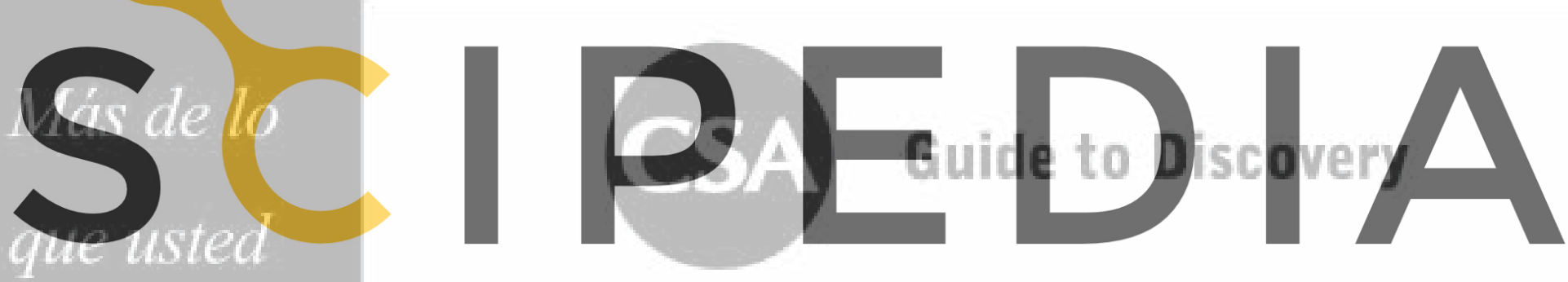

Register for free at https//www.scipedia.com to download the version without the watermark imagina.

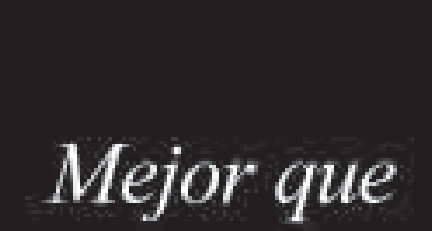

antes...

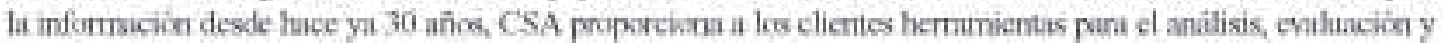
estadisticus abetnís ak las solucenones de búequosta.

Más de lo que usted piensa...

- MultiSearch - la solución fédetuda de búsquech basada in CSA Iltumina

- Scholar Profiles - innovidoe acceso al comecridi medianxe palabra clave

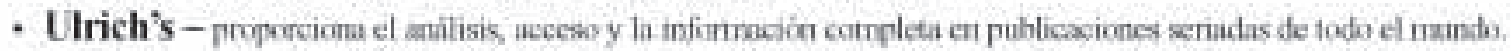

\section{Mejor que antes...}

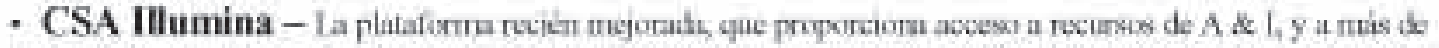
100 recursos a texto conipleto

\section{Guide to Discovery}

$\operatorname{cs} A$ 4640 Kinumpate Cuscude Way Dxiond ox4 235 United Kingiom

p +44 1865 336250 f +44 IB65 336258 e tivengras osar wwr.esa.chm

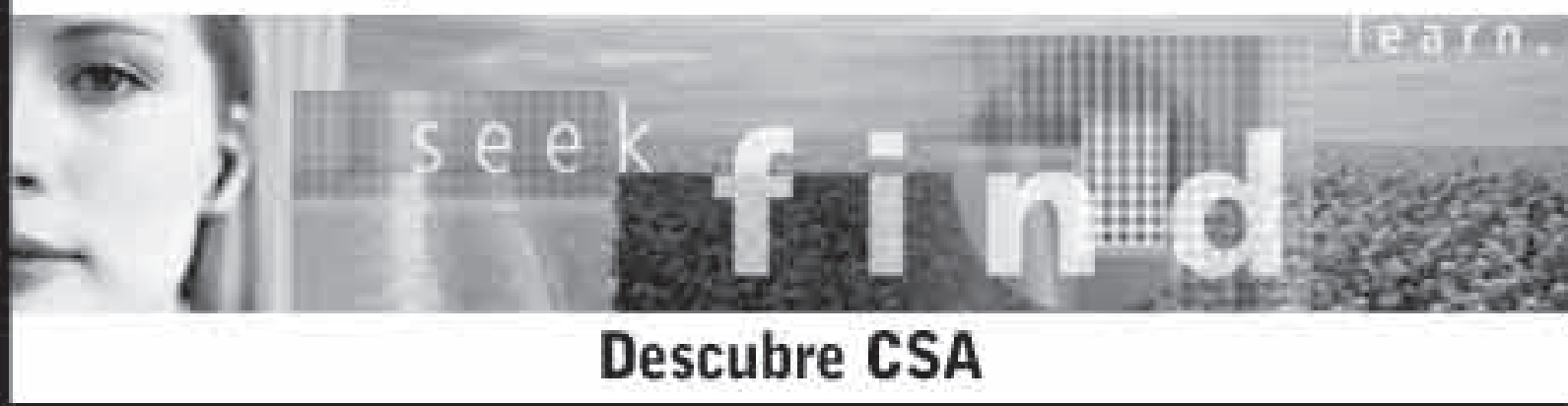

